\title{
Prevalence of Organic Mental Disorders in a General Hospital in Izhevsk, Russia
}

\author{
Sergei Pakriev* \\ Department of Psychiatry, Izhevsk State Medical Academy, Izhevsk, Russia
}

*Corresponding author: Sergei Pakriev, Department of Psychiatry, Izhevsk State Medical Academy, Izhevsk, Russia

\begin{abstract}
Background and Objectives: At the moment, studies of organic mental disorders (OMD) in in-patients of therapeutic units in Udmurtia are limited. The paper's objective was to study the prevalence and risk factors of OMD in medical patients in one of the municipal hospitals of Izhevsk.

Methods: The subjects (323 patients aged from 18 to 59 years) were selected using the method of continuous sampling. All subjects were asked to answer the questions from the Russian version of the Brief International Neuropsychiatric Questionnaire (MINI 5.0.0.).

Results: The prevalence of OMD was 55.1\%. OMD were more common in older patients (50-59 years) and in patients with chronic somatic diseases. $36.5 \%$ of patients with OMD were diagnosed with pre-dementia. The comorbidity of OMD with other mental disorders was statistically significant for depression and anxiety disorders.

Conclusion: Knowledge of OMD risk factors can contribute to early detection and adequate treatment of OMD in patients of general hospitals.
\end{abstract}

Keywords: Organic mental disorders; Prevalence; risk factors; General hospital

\section{Background and objectives}

According to scientific literature, the prevalence of organic mental disorders (OMD) in patients with somatic diseases is high [1-5]. Researchers note that OMD, along with depression and alcoholism, are the most frequent comorbid psychiatric disorders in therapeutic and surgical units [6-9]. Despite high epidemiological indicators, most of OMD in general hospitals are not recognized and not treated [6]. The consequence of comorbid OMD underdiagnosis is worsening of somatic pathology, increased resistance to therapy, and increased risk of disability [10]. OMD significantly impair social functioning and the quality of life [11]. It has been found that the degree of cognitive function deterioration in patients has a positive correlation with the duration of hospitalization and the cost of treatment [12-14].

Researchers emphasize that early, even immediate detection of organic mental disorders is extremely important [6]. At the moment, studies of organic mental disorders (OMD) in in-patients of therapeutic units in Udmurtia are limited. The paper's objective was to study the prevalence and risk factors of OMD in medical patients and identify correlative factors.

\section{Methods}

The research was carried out in Izhevsk, the capital of the Udmurt Republic, Russia, in therapeutic unit 1 of City Hospital No. 5. The hospital had two therapeutic units. Therapeutic unit 1 (65 beds) was intended for prearranged and emergency hospitalization of the working-age and retired patients from the district the hospital is formally assigned to serve (with an adult population of 57,000 people, about $70 \%$ of whom are working age). Therapeutic unit 2 was intended for the population with the official status of 'participants and disabled veterans of the Great Patriotic War' (note - Russian name for World War II) and equivalent categories of patients from Izhevsk. The average annual number of patients hospitalized to the first unit was 1,220 people, more than a half of them aged 50 and older. 
The subjects were selected using the method of continuous sampling. The group included every patient aged 18 to 59 referred to the hospital unit number 1 . The average length of hospitalization per patient was 18.3 days. A total of 352 patients were selected for the study. 29 of them (11 men and 18 women) were not included in the study for various reasons (refusal, severe somatic condition, etc.). Consequently, the study sample consisted of 323 patients, including 147 (45.5\%) men and 176 (54.5\%) women. Ethnic background of the study population: 214 (66.3\%) Russians, 77 (23.8) Udmurts and 32 (9.9\%) other. All participants were divided into the following age groups: 18-39 years- 37\%, 40-49 years$31 \%$ and $50-59$ years- $32 \% .71 .5 \%$ of the study population were hospitalized due to exacerbation of a chronic somatic disease and $28.5 \%$ - due to an acute somatic disease.

All subjects were asked to answer the questions from the Russian version of the Brief International Neuropsychiatric Questionnaire (MINI 5.0.0.) [15]. Additionally, the survey used the diagnostic criteria of ICD-10 for organic mental disorders and the criteria for tobacco addiction. MINI is a standardized diagnostic interview for major mental disorders according to DSM-IV and ICD-10. The reliability and validity of MINI correspond to SCID-P and CIDI, but an important advantage of MINI is that interviewing requires less time.
Information on somatic diagnoses, psychiatric consultations and prescribed psychotropic medications was obtained from medical records (medical history, patient records). Socio-demographic questions (gender, age, marital status, ethnic background, education and occupation) are part of MINI. Participation in the study was voluntary; the patients were informed of their right to refuse to participate. In case of consent, complete anonymity was guaranteed. The patients have signed a written 'Informed Consent'.

Questioning and interviewing in each case were conducted during the first 72 hours of hospitalization. The diagnostic survey was conducted by three medical doctors who had been trained to use MINI at the Department of Psychiatry of Izhevsk State Medical Academy. The STATISTICA 5.0 software was used to analyze the data. The following tests were used: the t-test to compare average values (average monthly income, average age, etc.) and the chisquare test to assess qualitative characteristics (gender, ethnic background, social status, etc.). To analyze comorbidity, the software Epi Info, Version 6 [16] was used. The OMD comorbidity was determined as follows: the probability index of concomitant disease in the population with OMD was divided by the probability index of concomitant disease in the population without OMD. The manuscript has been assessed by the Ethics Committee (Institutional Board Review) in the Izhevsk State Medical Academy.

\section{Results}

\section{A. Table 1 Shows a Breakdown of Diagnoses in the Study Population:}

Table 1: Somatic diseases and concomitant OMD.

\begin{tabular}{|c|c|c|c|}
\hline Somatic disease* & Total (N) & \% & With concomitant OMD N (\%) \\
\hline Circulatory system diseases & 96 & 29.7 & $79(82.3)$ \\
\hline Respiratory system diseases & 85 & 20.4 & $32(48.5)$ \\
\hline Digestive system diseases & 66 & 7.1 & $10(43.5)$ \\
\hline Genitourinary system diseases & 23 & 0.3 & $1(100)$ \\
\hline Endocrine system diseases & 1 & 6.5 & $14(66.7)$ \\
\hline Musculoskeletal system diseases & 21 & 1.2 & $3(75.0)$ \\
\hline Neoplasms & 4 & 4.3 & $3(21.4)$ \\
\hline Pregnancy complications & 14 & 0.9 & $2(66.7)$ \\
\hline Injuries and poisonings & 3 & 1.5 & $3(60.0)$ \\
\hline Diseases of the skin and subcutaneous tissue & 5 & 1.5 & $4(80.0)$ \\
\hline Disorders of the hematopoietic system & 5 & 28.5 & $16(17.4)$ \\
\hline Acute diseases & 92 & 71.5 & $162(70.1)$ \\
\hline Chronic diseases & 231 & 100 & $178(100)$ \\
\hline Total & 323 & & \\
\hline
\end{tabular}

* In case of concomitant somatic diseases, only the principle diagnosis was considered.

Acute diseases predominated in the group of patients with respiratory system disorders - 58.8\%, and disorders of other organs and systems were mainly represented by chronic diseases (genitourinary system- 78.3\%, digestive system- 78.8\%, cardiovascular- 94.8\%, and musculoskeletal- 100\%). Acute diseases were more often diagnosed in patients aged 18-39 (55.8\%), 
while chronic forms predominated in the age groups of 40-49 and $50-59$ years $-77.2 \%$ and $98.0 \%$ respectively. OMD were more often diagnosed in patients with chronic somatic diseases, especially those with diseases of the circulatory and musculoskeletal systems $-100 \%$ of the cases (Table 2).

Table 2: Most common somatic diseases with concomitant OMD.

\begin{tabular}{|c|c|c|c|}
\hline $\begin{array}{c}\text { Somatic } \\
\text { disease* }\end{array}$ & Total N (\%) & $\begin{array}{c}\text { Acute, with } \\
\text { concomitant } \\
\text { organic lesion } \\
\text { N (\%) }\end{array}$ & $\begin{array}{c}\text { Chronic, with } \\
\text { concomitant } \\
\text { organic lesion } \\
\text { N (\%) }\end{array}$ \\
\hline $\begin{array}{c}\text { Circulatory } \\
\text { system diseases }\end{array}$ & $96(29.7)$ & 0 & $79(100)$ \\
\hline $\begin{array}{c}\text { Respiratory } \\
\text { system diseases }\end{array}$ & $85(26.3)$ & $6(22.2)$ & $21(77.8)$ \\
\hline $\begin{array}{c}\text { Digestive } \\
\text { system diseases }\end{array}$ & $66(20.4)$ & $3(9.4)$ & $29(90.6)$ \\
\hline $\begin{array}{c}\text { Musculoskeletal } \\
\text { system diseases }\end{array}$ & $21(6.5)$ & 0 & $14(100)$ \\
\hline
\end{tabular}

The OMD prevalence in the sample was $55.1 \%$ (178 cases). The average age of the respondents with OMD was 46.6 years (Std. Dev. = 10.2). The average OMD duration was 6.4 years, with the minimum less than one year and the maximum of 45 years (Std. Dev. $=6.4$ ).

\section{B. The Breakdown of OMD is Given Below (Table 3):}

Table 3: Organic disorders.

\begin{tabular}{|l|c|c|}
\hline \multicolumn{1}{|c|}{ Diagnosis } & No. & \% \\
\hline Organic asthenic disorder (F 06.6) & 91 & 51.1 \\
\hline Organic personality disorder (F07.0) & 17 & 9.6 \\
\hline $\begin{array}{l}\text { Organic asthenic disorder with mild cognitive } \\
\text { disorder (F06.6+F06.7) }\end{array}$ & 36 & 20.2 \\
\hline $\begin{array}{l}\text { Organic personality disorder with mild cognitive } \\
\text { disorder (F07.0+F06.7) }\end{array}$ & 29 & 16.3 \\
\hline Dementia F0 & 5 & 2.8 \\
\hline Total & 178 & 100 \\
\hline
\end{tabular}

In terms of socio-demographic factors, a reliable correlation with the age of the patients was identified: OMD in the age groups of 18-39, 40-49 and 50-59 years were diagnosed in 19.7\%, 33.2\% and $47.2 \%$ of the cases respectively $(\mathrm{P}=0.000)$. There was no statistically significant correlation between OMD and ethnic background, marital status, education or social status. The tendency to a greater predisposition to OMD in women (56.7\% versus $43.3 \%$ in men) was identified. There were other psychiatric disorders diagnosed in the sample: depressive disorders $-20.7 \%$, alcohol dependence-24.8\%, tobacco dependence $-45.2 \%$, social phobias - 13.3\%, other anxiety disorders - $6.5 \%$ (ICD-10 codes: F40.01, F41.0, F41.1, F42.8). The comorbidity of OMD with other mental disorders was statistically significant for depression and anxiety disorders (Table 4). $20.2 \%$ of patients with OMD were counseled by a psychiatrist.
Table 4: OMD comorbidity with other mental disorders.

\begin{tabular}{|c|c|c|c|}
\hline $\begin{array}{c}\text { Comorbid } \\
\text { disorders }\end{array}$ & $\begin{array}{c}\text { Subjects with } \\
\text { OMD (\%) }\end{array}$ & Odds ratio & $\mathbf{9 5 \% ~ C I ~}$ \\
\hline Depression & 74.6 & 2.94 & $1.55-5.62$ \\
\hline Social phobias & 58.1 & 1.15 & $0.58-2.32$ \\
\hline $\begin{array}{c}\text { Other anxiety } \\
\text { disorders }\end{array}$ & 81.1 & 3.72 & $1.14-13.42$ \\
\hline $\begin{array}{c}\text { Alcohol } \\
\text { dependence }\end{array}$ & 60 & 1.3 & $0.76-2.25$ \\
\hline $\begin{array}{c}\text { Tobacco } \\
\text { dependence }\end{array}$ & 56.2 & 1.08 & $0.68-1.72$ \\
\hline
\end{tabular}

\section{Discussion and Conclusion}

According to numerous Russian and foreign studies, it has been proven that there are strong structural links between comorbid organic mental disorders and somatic disorders [1] - this fact was confirmed in our study. More than a half of the sample in this study had OMD (55.1\%). The most common OMD diagnosis was organic asthenic disorder (51.1\% of all OMD). $36.5 \%$ of the respondents with OMD had decreased cognitive functions - pre-dementia, and $2.8 \%$ were diagnosed with dementia. It is noteworthy that a lot of respondents in the sample (most of whom were at their working age) were diagnosed with pre-dementia or, as it is called in some sources, mild cognitive impairment (MCI) [17]. According to different data, the prevalence of the MCI syndrome among elderly and senile patients (65 years and older) varies from $7 \%$ to $38 \%$. It is known there is an increased risk of the MCI syndrome transition to dementia within the next 3 to 5 years [18]. According to a group of researchers from New York University, 42\% of people initially diagnosed with the MCI syndrome were diagnosed with dementia in 5 years with only $7 \%$ of the patients being in the age-norm group [19].

The researchers emphasize it is not a somatic pathology but its severity and duration that play a role in the development of OMD. Apparently this is why OMD were statistically more often diagnosed in patients with chronic rather than acute somatic diseases $(70.1 \%$ vs $17.4 \%$ ). Moreover, $100 \%$ of the respondents with diseases of the circulatory or musculoskeletal systems were diagnosed with OMD. High occurrence of OMD was observed among patients with diseases of the digestive and respiratory systems - 90.6\% and $77.8 \%$ respectively.

There was no correlation between OMD and such sociodemographic factors as gender, ethnicity, marital status, education or social status. There was a reliable correlation between OMD and the age of the patients, probably because of the greater occurrence of chronic somatic diseases and accumulation of cerebrovascular diseases in elderly patients [4]. Thus, the epidemiological indicators of OMD in the general hospital were extremely high, especially among patients with chronic diseases. One third of patients with OMD were diagnosed with mild cognitive impairment, and 
according to medical sources, there is a high risk that this condition may transform into dementia in the next few years.

Such results may indicate insufficient diagnostics and lack of OMD treatment. The reasons for the under-diagnosis may be insufficient psychiatric care in hospitals and lack of awareness among therapists of the OMD clinical picture. Awareness of epidemiology and risk factors can contribute to early detection and treatment of OMD. Identification and appropriate treatment of OMD is an extremely important task due to the unfavorable prognosis.

\section{References}

1. Odarchenko SS (2009) Non-psychotic psychiatric disorders of later age. Abstract of the dissertation for the degree of Doctor of Medicine. Tomsk, p.10.

2. Sheremetyeva II (2008) Exogenous-organic mental disorders in the general structure of mental disorders (clinical and epidemiological study). Abstract of the dissertation for the degree of Doctor of Medicine. Moscow.

3. Piven BN (2007) Sheremetyeva Exogenous-organic mental disorders in men and women: comparative aspect. Russian Psychiatric Journal (3): 44-47.

4. Komarova YeV (2007) Mental disorders with underlying cerebrovascular pathology (cerebral atherosclerosis, arterial hypertension) and their assessment during postmortem forensic psychiatric examinations in civil trials. Abstract of the dissertation for the degree of Doctor of Medicine.

5. Lebedeva VF (2007) Mental disorders with underlying somatic diseases (epidemiological, clinical, and rehabilitation aspects). Abstract of the dissertation for the degree of Doctor of Medicine. Tomsk.

6. MO Agbayewa (1983) Recognition of organic mental disorders by physicians. Can Med Assoc J 128(8): 927-928.

7. Arolt V, Driessen M, Bangert Verleger A, Neubauer H, Schürmann A, et al. (1995) Psychiatric disorders in hospitalized internal medicine and surgical patients. Prevalence and need for treatment. 66(9): 670-677.

8. Smaira SI, Kerr Corrêa F, Contel JO (2003) Psychiatric disorders and psychiatric consultation in a general hospital: a case- control study. Rev Bras Psiquiatr 25(1): 18-25.
9. Rothenhäusler HB (2006) Mental disorders in general hospital patients. Psychiatr Danub 18(3-4): 183-192.

10. Kruglov LS (2007) Vascular diseases of the brain with psychoorganic syndrome in elderly patients / study of clinical and social characteristics, their values and changes during therapy. Abstract of the dissertation for the degree of Doctor of Medicine.

11. Beznos SA (2008) Evaluation of the influence of various pathogenic factors on social functioning and quality of life of mentally ill elderly patients. Abstract of the dissertation for the degree of Doctor of Medicine, p. 20

12. Furlanetto LM, da Silva RV, Bueno JR (2003) The impact of psychiatric comorbidity on length of stay of medical inpatients. Gen Hosp Psychiatry 25(1): 14-19.

13. Sebestyén G, Hamar M, Bíró L, Kovács G, Gazdag G (2006) Impact of comorbid psychiatric disorders on the length of stay and the cost of medical treatment among geriatric patients treated with internal medicine wards. Psychiatr Hung 21(5): 386-392.

14. Hochlehnert A, Niehoff D, Herzog W, Löwe B (2007) Elevated costs of treatment in medical inpatients with psychiatric comorbidity are not reflected in the German DRG-system. Psychother Psychosom Med Psychol 57(2): 70-75.

15. Sheehan D, Lecrubier Y, Harnett Sheehan K (1998) The Mini International Neuropsychiatric Interview (M.I.N.I.): The Development and Validation of a Structured Diagnostic Psychiatric Interview for DSM-IV and ICD-10. J Clin Psychiatry 59(Suppl 20): 22-33.

16. Dean AG, Dean JA, Coulombier D, Anthony H, Dicker (1995) Epi Info, Version 6: A word processing, database, and statistics program for epidemiology on microcomputers. Centers for Disease Control and Prevention, Atlanta, Georgia, USA.

17. Fedorova Ya B (2007) The mild cognitive impairment syndrome in elderly patients (psychopathological structure, psychometric and neuropsychological characteristics, prognosis). Abstract of the dissertation for the degree of Doctor of Medicine. Moscow.

18. Gavrilova SI, Fedorova Ya B, Roshina IF, Korovaytseva GI (2007) The prognosis of mild cognitive impairment according to the two-year clinical follow-up study. Korsakov Journal of Neurology and Psychiatry 1: 4-10.

19. Golomb J, Kluger A, Garrard P, Ferris S (2001) Clinician's Manual on Mild Cognitive Impairment. UK: Science Press, London.
To Submit Your Article Click Here:

This work is licensed under Creative Commons Attribution 4.0 License

Submit Article

DOI: $10.32474 / 0 J N B D .2019 .02 .000138$

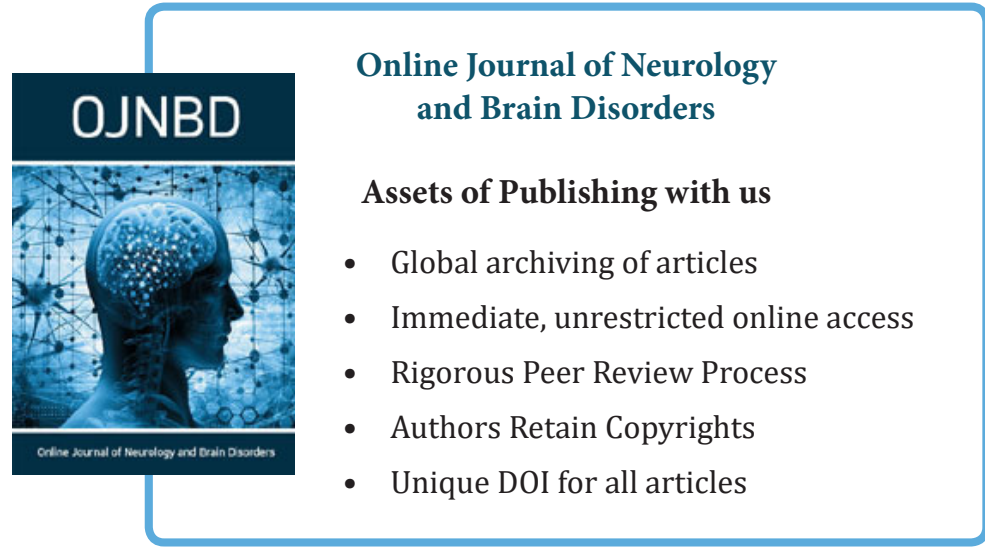

